\title{
Assessment of the influence of a biorational insecticide of the juvenoid class on the state of fruit cenoses
}

\author{
Marina Podgornaya*, Svetlana Prah, Anfisa Vasilchenko, and Nadezhda Didenko \\ Federal State Budget Scientific Institution «North Caucasian Federal Scientific Center of \\ Horticulture, Viticulture, Wine-making», str. 40 Let Pobedy, 39, 350901 Krasnodar, Russia
}

\begin{abstract}
The dominant pests in the apple and plum cenoses are representatives of the tortrix family (Tortricidae) on the apple - the codling moth (Cydia pomonella L.), on the plum - the plum moth (Grapholitha funebrana Mats.), which develop in the region of southern Russia in three full generations. The loss of yield from the vital activity of these phytophages can reach $60-80 \%$. It has been established that the inclusion of a 2-fold application of the insecticide Insegar, WDG in the apple and plum protection system allows preserving $98.9 \%$ of apple fruits and $94.6-99.2 \%$ of plum fruits. The stimulating effect of the use of insecticides of the juvenile group on the agrobiological indicators of the apple-tree variety Golden Reinders and the plum Kabardinskaya early was revealed, namely, the increase in the length of the one-year growth. It has been proven that the double application of Insegar, WDG in apple and plum plantations does not lead to violation of hygienic standards for the content of fenoxycarb in soil and fruits.
\end{abstract}

\section{Introduction}

In the structure of perennial plantations of the Krasnodar Territory, the main area is occupied by pome and stone fruit crops, of which 24 thousand hectares are apple orchards and 4.7 thousand hectares are plum plantings. The dominant fruit-damaging objects in both crops are representatives of the Tortricidae family: the apple moth (Cydia pomonella L.) on the apple tree, and the plum moth (Grapholitha funebrana Mats.) on the plum. In the changing weather and climatic conditions of the south of Russia, both species develop in three complete generations. The control of the number of moths is achieved through repeated treatments with insecticides of various chemical classes, which entails negative consequences: an increased level of residual amounts of pesticides, changes in the biodiversity of the garden fauna, a decrease in the ecological self-regulation of cenoses [1, 2].

The increasing impact of anthropogenic and abiotic factors on agricultural landscapes is a priority task. Since 2017, in the Kuban zone of the central subzone of the Krasnodar Territory, studies have begun to determine the effect of juvenoid class insecticides (active

\footnotetext{
${ }^{*}$ Corresponding author: plantprotecshion@yandex.ru
} 
ingredient fenoxycarb) on apple and plum cenoses [3]. Currently, 4 insecticides based on the active ingredient fenoxycarb are registered in the Russian Federation on perennial crops: Insegar, WDG (LLC (Limited Liability Company) "Syngenta"), Akarb, WDG (LLC "Agroprogress Kemikals"), Fazis, WP (LLC "Himagromarketing. RU") and Fora, WP (LLC "Rosagrokhim"). Insegar, WDG and Acarb, WDG (250 g / kg fenoxycarb) are approved for use on fruit crops by the "Directory of pesticides and agrochemicals approved for use on the territory of the Russian Federation" with a consumption rate of $0,6 \mathrm{~kg} / \mathrm{ha}$ for apple trees, 0,4 $\mathrm{kg} / \mathrm{ha}$ for plums, no more than three times per season.

Insegar, WDG - enteric-contact insecticide, belongs to the carbamate class, insect growth regulator group (IGR), juvenile hormone analog (JHA) [4]. The active ingredient fenoxycarb, contained in the preparation, affects insects from various orders: Lepidoptera, Coleoptera, Homoptera, Dictyoptera, Diptera and Orthoptera, and affects the phases of arthropod development, such as morphogenesis, embryogenesis, reproducibility, and pheromone production. Fenoxycarb was developed and marketed in the United States in 1980. This preparation acts on the endocrine system of insects, mimicking the hormone $\mathrm{JH}$, preventing the metamorphosis of an individual - JH does not allow the steroid ecdysone to activate the genes responsible for molting, thereby preventing it [5]. As a result, the transformation from the embryonic state to the larva is disrupted, from the larva to the pupa, and then to the adult reproductive organism - developmental anomalies occur, which reduce the survival of organisms. In comparison with conventional insecticides that cause the rapid death of insects, the use of Insegar, WDG reduces fertility and causes a decrease in the population in the next generation. At the same time, the use of JHA at the older ages of larvae leads to the fact that the development time of eggs, larvae and pupae significantly increases in the generation of offspring, and adult insects lose their ability to reproduce $[6,7,8,9,10]$.

Toxicological research have found that the active substance of this preparation is sedentary in soil, water and plants, rapidly decomposes, and does not accumulate in living organisms. The high permeability and stability of fenoxycarb explain its high biological activity, since the insecticide is rapidly destroyed by microbes in the soil environment and is less toxic than most preparations, therefore Insegar, WDG is one of the important elements in the ecological system of lepidoptera pest control [11].

The purpose of these research was to obtain experimental data on the formation of the functional structure of biosystems of perennial plantations when using drugs of the juvenoid class and to establish the mechanisms of their transformation in agrocenoses of apple and plum orchards.

\section{Materials and methods}

To obtain new experimental data on the formation of the functional structure of biosystems plantations perennial when using preparations of the juvenoid class and to establish the mechanisms of their transformation in agrocenoses orchard an apple and plum, the following insecticides were included in the studies: insect growth and development regulator Insegar, WDG (250 g / kg fenoxycarb).

The research was carried out in the II climatic zone of chernozems of the forest-steppe and steppe regions (North Caucasian region of cultivation of crops), in the Kuban zone of the central subzone of Krasnodar Territory: ZAO EPF "Tsentralnoe" and on the vegetation station NCFSCHVW in 2017-2020. The soil on the plots is the Ciscaucasian leached chernozem, low-humus, super-powerful, the humus content in the arable horizon is $3.2 \%$, $\mathrm{pH}$ is 6.5-7.0. Production and microplot field experiments were carried out on an apple of the Golden Reynders variety and a plum of the Kabardinskaya early variety.

The size of the experimental plots is 6 trees in 4 replicates, the placement is randomized. Plum planting in 1993, scheme $5 \times 2 \mathrm{~m}$, tree height 2.0-2.5 m, combined crown formation. 
The apple tree was planted in 2009 , the scheme is $4 \times 1.2 \mathrm{~m} 2$, the height of the trees is $1.5-1.7$ $\mathrm{m}$, the parent stock is M9, the formation of the crown is fusiform.

Dates of insecticide application were determined based on the results of pheromone monitoring. Treatments were carried out during the mass summer - at the beginning of the laying of eggs of the first and second generation.

Sampling for tracking the dynamics of decomposition of fenoxycarb was carried out on the day of the last treatment (after 5 hours), then on days 10, 20, 30 and 40. Samples were taken from the upper soil horizon - 0-20 cm, at a distance of 1 meter from the bole $[12,13]$. The extraction of fenoxycarb from the samples was carried out with methanol, according to MUK 4.1.2272-07, purification using liquid-liquid extraction, hexane was used as a nonpolar solvent, as the aqueous phase at the beginning of the analysis - a saturated solution of sodium chloride, then a $0.5 \%$ aqueous solution of sodium bicarbonate. The subsequent purification of the extract was carried out on a column with silica gel and on a Diapak C8 concentrating cartridge [14].

The quantitative determination of fenoxycarb was carried out on a liquid chromatograph with an ultraviolet detector with a variable wavelength (Knauer, Germany) on a column with Diasfer 110-C18 adsorbent $(5 \mu \mathrm{m})$, size $\mathrm{L}=15 \mathrm{~cm}, \mathrm{~d}=4 \mathrm{~mm}$. When determining, the eluent was used $-\mathrm{C}_{2} \mathrm{H}_{3} \mathrm{~N}-0.5 \mathrm{M} \mathrm{H}_{3} \mathrm{PO}_{4}$ in a ratio of $65: 35$ for apple fruits (flow rate $0.8 \mathrm{ml} / \mathrm{min}$ ) and 50:50 for plum fruits and soil (speed $-0.9 \mathrm{ml} / \mathrm{min}$ ). The release time of fenoxycarb in apple samples is $12.2 \pm 0.1 \mathrm{~min}$; plum and soil samples $-4.8 \pm 0.1 \mathrm{~min}$. All calculations were performed using the ClarityChrom program, the standard deviation for all samples was 3\% $[3,15]$.

\section{Results and discussion}

Over the past ten years in the Krasnodar Territory, the average annual air temperature has increased by $0.8^{\circ} \mathrm{C}$, the most intense increase occurs in the winter period - in the flat part of the region by $2.1-2.8^{\circ} \mathrm{C}$, in the mountainous part - by $1.2-1.8^{\circ} \mathrm{C}$. In $2018-2020$. there was a sharp increase in the average daily temperature in the Kuban zone in the spring $\left(5.5^{\circ} \mathrm{C}\right.$ in March; $26.5{ }^{\circ} \mathrm{C}$ in May), in the Black Sea zone a gradual increase in the average daily temperature $\left(6.1{ }^{\circ} \mathrm{C}\right.$ in March; $19{ }^{\circ} \mathrm{C}$ in May) [16].

Long-term monitoring of the development of apple and plum moths shows that due to the changing weather and climatic conditions of the region, there is an increase in the number of phytophages by $15-50 \%$ compared to the average long-term indicators. Phenological changes in the biology of pests are the earlier appearance of the first specimens of overwintered butterflies. In 2020, the appearance of the imagos of G. funebrana was noted in the first ten days of April, which is 25 days earlier than in 2017 and corresponds to the average long-term indicators; the beginning of flight of $C$. pomonella was recorded in the middle of the second decade of April, which is 9 days earlier than the average long-term data.

It has been established that the flight of the first generation $G$. funebrana moths is extended, lasts 1.5-2 months. In 2018-2020, the flight duration is reduced to 30-40 days, the fly of the second generation begins one month earlier than the multi-year terms (Figure 1). The tendency to change the beginning of flight of the first overwintered generation and the lengthening of the flight time of the last generation in the last decade has been noted for all lepidoptera pests of the orchard. 


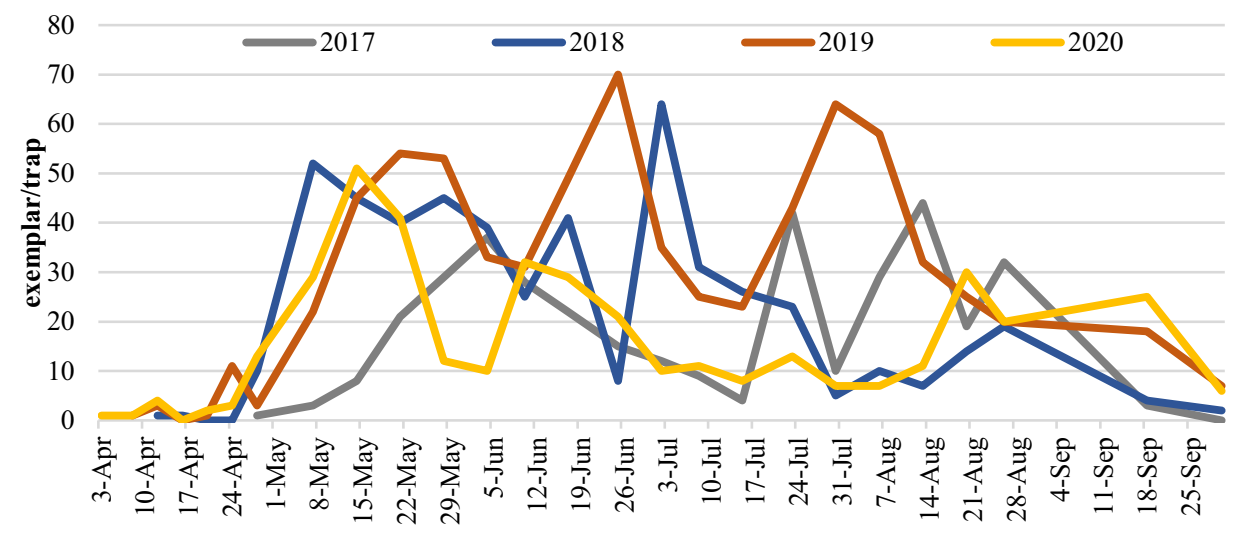

Fig. 1. Dynamics butterflies flying of plum moth (the vegetation station FSBSI NCFSCHVW, the plum Kabardinskaya early, 2017-2020).

Stable results have been obtained on the highly effective action in extreme weather conditions of the growth and development regulator of insects (Insegar, WDG), as well as a drug from the class of chitin synthesis inhibitors Dimilin, WP (250 g/ kg tiflubenzuron). It was found that the inclusion in the system of apple protection against fruit-damaging pests of the 2-fold application of Insegar, WDG allows saving $98.9 \%$ of the fruits, with the use of Dimilin, SP $-96.2 \%$, with $38.9 \%$ of fruit damage in the control variant (table 1).

Table 1. Influence of insecticides on apple yield, variety Golden Reinders, Krasnodar Territory, 2017-2020

\begin{tabular}{|c|c|c|c|c|c|c|c|c|c|}
\hline \multirow[t]{2}{*}{ Experience variant } & \multirow{2}{*}{$\begin{array}{c}\text { Application } \\
\text { rate of the } \\
\text { preparation, } \\
\text { kg/ha }\end{array}$} & \multirow{2}{*}{$\begin{array}{c}\text { Multi } \\
\text { plicity } \\
\text { of } \\
\text { treatm } \\
\text { ent }\end{array}$} & \multicolumn{2}{|c|}{$\begin{array}{c}\text { BE, } \% \\
\text { harvest fruits }\end{array}$} & \multicolumn{2}{|c|}{$\begin{array}{l}\text { Crop with } \\
\text { 1st tree }\end{array}$} & \multicolumn{3}{|c|}{$\begin{array}{c}\text { Fruit crop yield } \\
\text { by varieties, } \\
\%\end{array}$} \\
\hline & & & $\begin{array}{c}\text { drop, } \\
\%\end{array}$ & $\begin{array}{c}\text { crop, } \\
\%\end{array}$ & kg & $\begin{array}{c}\% \text { to } \\
\text { control }\end{array}$ & $\begin{array}{l}\text { prime } \\
\text { grade }\end{array}$ & $\begin{array}{c}1 \\
\text { grade }\end{array}$ & \begin{tabular}{|c|}
2 \\
grade
\end{tabular} \\
\hline $\begin{array}{l}\text { Insegar, WDG (250 } \\
\mathrm{g} / \mathrm{kg})\end{array}$ & 0,6 & 2 & 96,8 & 98,9 & 10,4 & 158,7 & 98,0 & 2,0 & 0,0 \\
\hline $\begin{array}{l}\text { Dimilin, WP (400 g/l) } \\
\text { (standard) }\end{array}$ & 1,0 & 2 & 92,3 & 96,2 & 9,5 & 155,7 & 96,0 & 4,0 & 0,0 \\
\hline $\begin{array}{l}\text { Control (without } \\
\text { treatment), } \\
\% \text { damaged fruits }\end{array}$ & - & - & 51,2 & 38,9 & 6,1 & 100 & 60,0 & 30,0 & 10,0 \\
\hline $\operatorname{LSD}_{05} * *$ & & & & & 2,8 & & & & \\
\hline
\end{tabular}

* BE - biological effect; ** LSD - Least Significant Difference

The use of Insegar, WDG in the system of protection of plums against the plum moth provides control of phytophages the number in the removable crop at the level of 94.6-99.2\%, with damage to removable fruits in the control - 4.5-6.8\%, during the season in the dead $38.4-51.7 \%$ (Figure 2). 


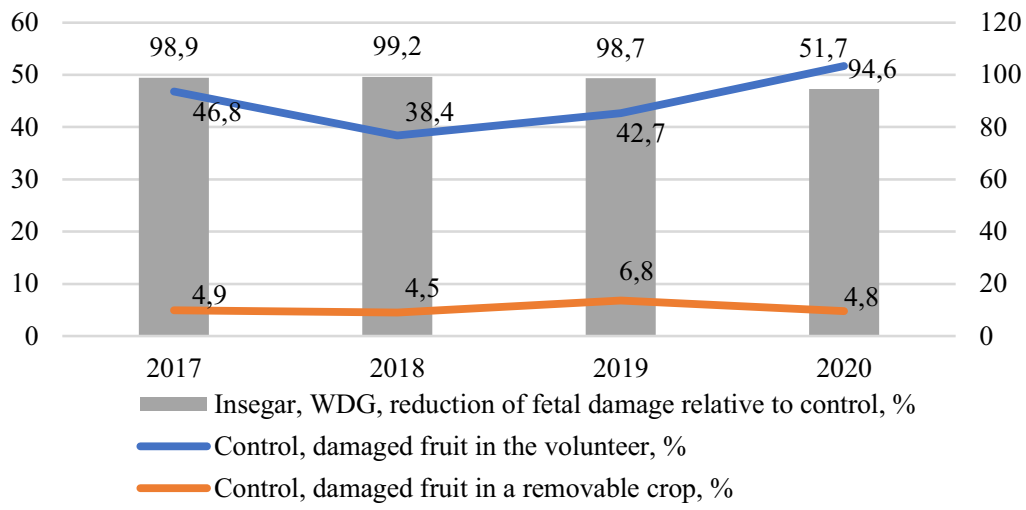

Fig. 2. Biological effectiveness of the insecticide Insegar, WDG against the plum moth, (the vegetation station FSBSI NCFSCHVW, the plum Kabardinskaya early, 2017-2020).

The stimulating effect of the use of insecticides of the juvenile group on the biometric indicators of the apple-tree variety Golden Reinders and the plum Kabardinskaya early was revealed. On average, over four years of research, it was found that the use of a regulator of growth and development of insects (Insegar, WDG) leads to an increase in the length of the one-year growth of an apple tree, in comparison with the control, by $25.2-47.5 \%$, but does not affect the leaf area records (Figure 3,4).

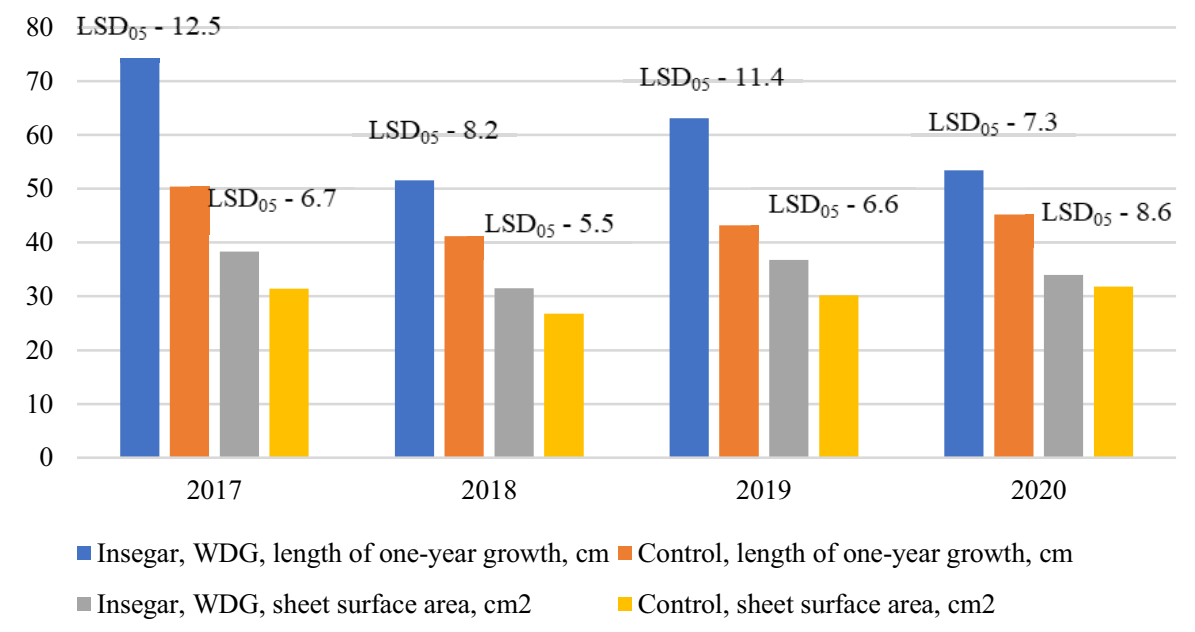

Fig. 3. Biometric indicators of an apple tree, after double use of the preparation Insegar, WDG, 20172020 . 


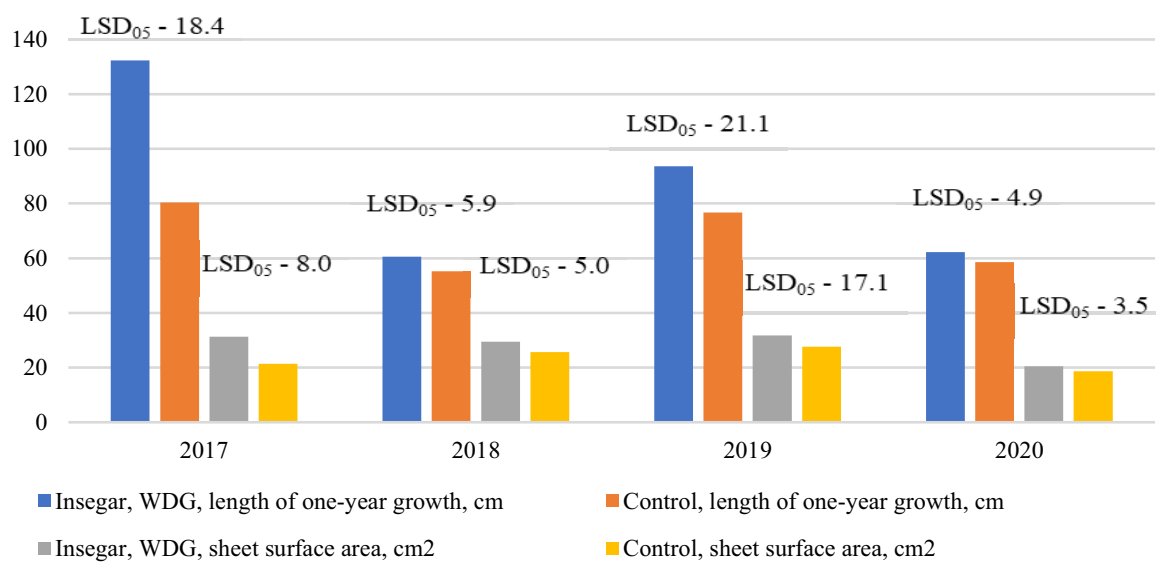

Fig. 4. Biometric indices of plum, after double use of the preparation Insegar, WDG 2017-2020.

Similar results were obtained on the plum; after the application of the insecticide Insegar, WDG, an increase in the growth of annual shoots by $5.9-39.9 \%$ was noted. Statistical characteristics of variation series and confidence intervals for general averages with a $95 \%$ level of probability of quantitative variability in shoot length and leaf area for 2017-2020 have been determined.

It was found that two-fold application of insecticides with an interval between treatments of 30 days with the active substance fenoxycarb in apple and plum agrocenoses does not lead to violation of hygienic standards (Figures 5, 6) [17].

It was revealed that at the end of the "Waiting Period" the indicators of the content of fenoxycarb in the fruits of plum and apple trees did not exceed the maximum permissible levels (MPL). In the soil of garden agrocenoses, fenoxycarb completely decomposes after 30 days.

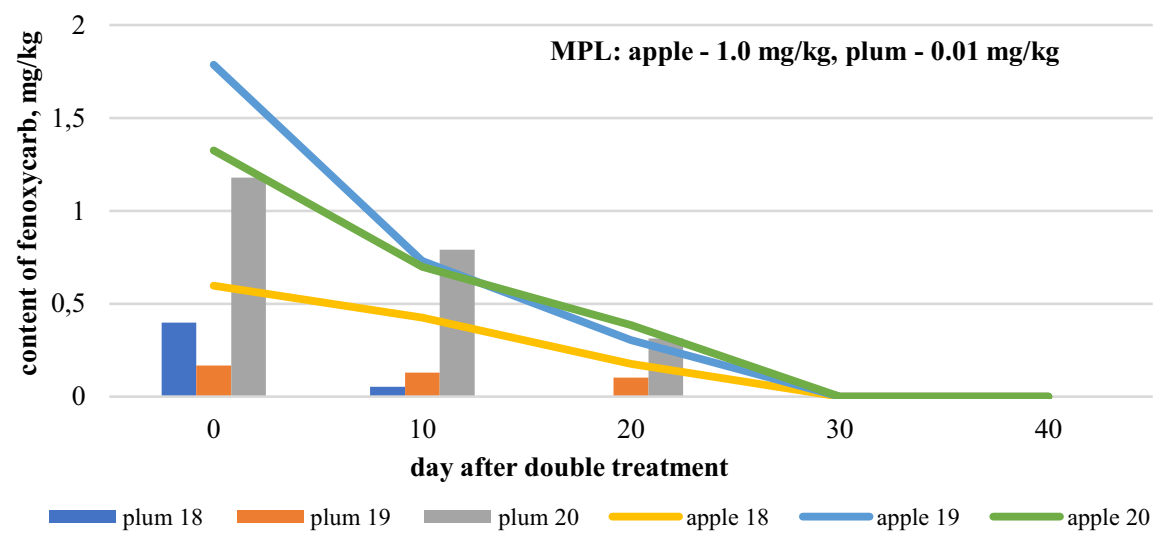

Fig. 5. The content of fenoxycarb in the raw mass of plum and apple fruits, $\mathrm{mg} / \mathrm{kg}$ 


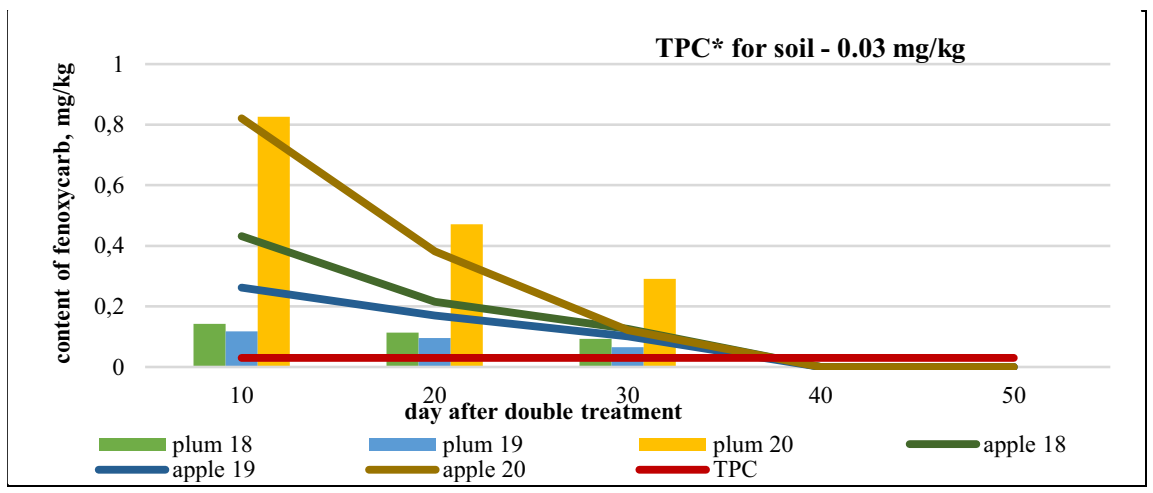

Fig. 6. The content of fenoxycarb in the soil under plantings of plum and apple trees, $\mathrm{mg} / \mathrm{kg}$

* TPC - tentative allowable concentration.

\section{Conclusions}

Thus, as a result of 4-year studies, it was found that under extreme weather conditions in the south of Russia, a stable and highly effective effect of the regulator of the growth and development of insects in controlling the number of apple and plum moths was noted. Inclusion in the apple and plum tree protection system of the 2-fold application of the insecticide Insegar, WDG allows saving $98.9 \%$ of apple fruits and $94.6-99.2 \%$ of plum fruits. The stimulating effect of the use of insecticides of the juvenile group on the biometric indicators of the apple-tree variety Golden Reinders and the plum Kabardinskaya early, namely, an increase in the length of one-year growth, was revealed. It has been proven that the double application of Insegar, WDG in apple and plum plantations does not lead to violation of hygienic standards for the content of fenoxycarb in soil and fruits.

\section{Reference}

1. F. Sánchez-Bayo, K. A. G. Wyckhuys, ScienceDirect. Biol. Conserv, 232, 8 (2019)

2. A.C. Costamagna, D.A. Landis, M.J. Brewer, Biological Control, 45(3), 368 (2008)

3. M.E. Podgornaya, A. Vasilchenko, N. Didenko, BIO Web of Conferences, 21, 4 (2020)

4. T. Chen., T.-X. Liu, Florida Entomologist, 84(4), 628 (2001)

5. Y. Sik Lee, J. Son, J. Wee, Y. Kim, J. Hong, K. Cho, Journal of Asia-Pacific Entomology, 23(1), 214 (2020)

6. X. Zhou, L.M. Riddiford, Development, 129, 2259 (2002)

7. G. H. Abro, T. S. Corbitt, P. T. Christie, D. J. Wright, Journal of Insect Science, 15(1), $82(2015)$

8. J. Miyamoto, M. Hirano, Y. Takimoto, M. Hatakoshi, Pest Cont Enhance Environ, 524, 144 (1993)

9. J.J. Sullivan, Reviews of Environmental Contamination and Toxicology, 202, 155 (2010)

10. J.N. Tasei, A review. Apidologie, 32, 527 (2001)

11. A.F. Grapov, M. Ya. Putin, Agrochemistry, 11, 119 (1988)

12. GOST R 58595-2019 Soils. Sampling, 8 (2019) 
13. MU 2051-79. Methods for the determination of trace amounts of pesticides in food, feed and the environment, 47 (1983)

14. MUK 4.1.2272-07. Determination of residual amounts of phenoxycarb in apples, plums and grapes by high performance liquid chromatography. Methodical instructions (2009)

15. Podgornaya M.E., Vasilchenko A.V., Didenko N.A., Chernov V.V., Tavrichesky Bulletin of Agrarian Science, 2(22), 107 (2020)

16. G. Ivashkov, Moskovsky Komsomolets (2019)

17. SanPiN 1.2.3685-21. Hygienic standards and requirements for ensuring the safety and (or) harmlessness of environmental factors to humans, 829 (2021) 